\title{
Modification by an Ice Cover of the Tide in James Bay and Hudson Bay GABRIEL GODIN ${ }^{1}$
}

(Received 24 May 1983; accepted in revised form 24 April 1985)

\begin{abstract}
The tide in Hudson Bay-James Bay is mainly semidiurnal. Admittance calculations between a reference signal and the water level observed at some gauging sites reveal that in the interior of Hudson Bay-James Bay the tide occurs earlier and its amplitude is reduced after the formation of an ice cover.
\end{abstract}

Key words: tides, ice, modification of tides, Hudson Bay

RÉSUMÉ. La marée dans les baies d'Hudson et James est surtout semi-diurne. Des calculs d'entrée entre un signal de référence et le niveau d'eau observé à quelques sites de mesure signalent qu'à l'intérieur de ces baies, la marée se produit plus tôt et son amplitude est réduite avec la formation d'une couche de glace.

Mots clés: marées, glace, modification des marées, baie d'Hudson

Traduit pour le journal par Maurice Guibord.

\section{INTRODUCTION}

Later arrivals of high water and decreases in the range of the tide have been noticed during winter at some arctic gauging sites (Zubov, 1945; Henry and Foreman, 1977), suggesting that the presence of an ice cover modifies the tide in northern regions. If ice is viewed as a damping mechanism, it can be expected to cause delays in the occurrence of high or low water and diminished tidal ranges in arctic and subarctic seas during winter. An earlier investigation of the tidal data available for Canadian waters (Godin and Barber, 1980; Godin, 1980) revealed that this hypothesis holds only in shallow semi-enclosed seas or at sites located behind extensive shelves where the tide is not generated locally. In fact, the tide is not significantly affected by the presence of ice, even in the most northerly latitudes, at sites located on the rim of the ocean or connected to it by deep channels. This is the case for Resolute (Fig. 1, \#1), Alert $\left(82^{\circ} 30^{\prime} \mathrm{N}, 62^{\circ} 19^{\prime} \mathrm{W}\right)$, Frobisher Bay $\left(63^{\circ} 43^{\prime} \mathrm{N}, 68^{\circ} 32^{\prime} \mathrm{W}\right)$, Rae Point $\left(75^{\circ} 22^{\prime} \mathrm{N}, 105^{\circ} 42^{\prime} \mathrm{W}\right)$, Lake Harbour (Fig. 1, \#2) and possibly Cape Parry $\left(70^{\circ} 09^{\prime} \mathrm{N}, 124^{\circ} 40^{\prime} \mathrm{W}\right)$. This has also been confirmed by a numerical model of the $\mathrm{M}_{2}$ tide in the Arctic Ocean that takes into account the effect of ice (Kowalik, 1981).

I have pursued this investigation using more recent data for Hudson Bay, a shallow sea with a good connection to the ocean. The local tide is dominated by its semidiurnal component, it is maintained by cooscillations with the Atlantic, and only a small portion of it is generated locally (Freeman and Murty, 1976).

\section{METHODS}

In order to detect a change in the tide, I calculated the cross spectrum between hourly observations on level y (observed at the station to be investigated) and level $\mathrm{x}$ (at a reference station located in a continuously ice-free area). A useful parameter is the admittance (Bendat and Piersol, 1966; Godin, 1976),

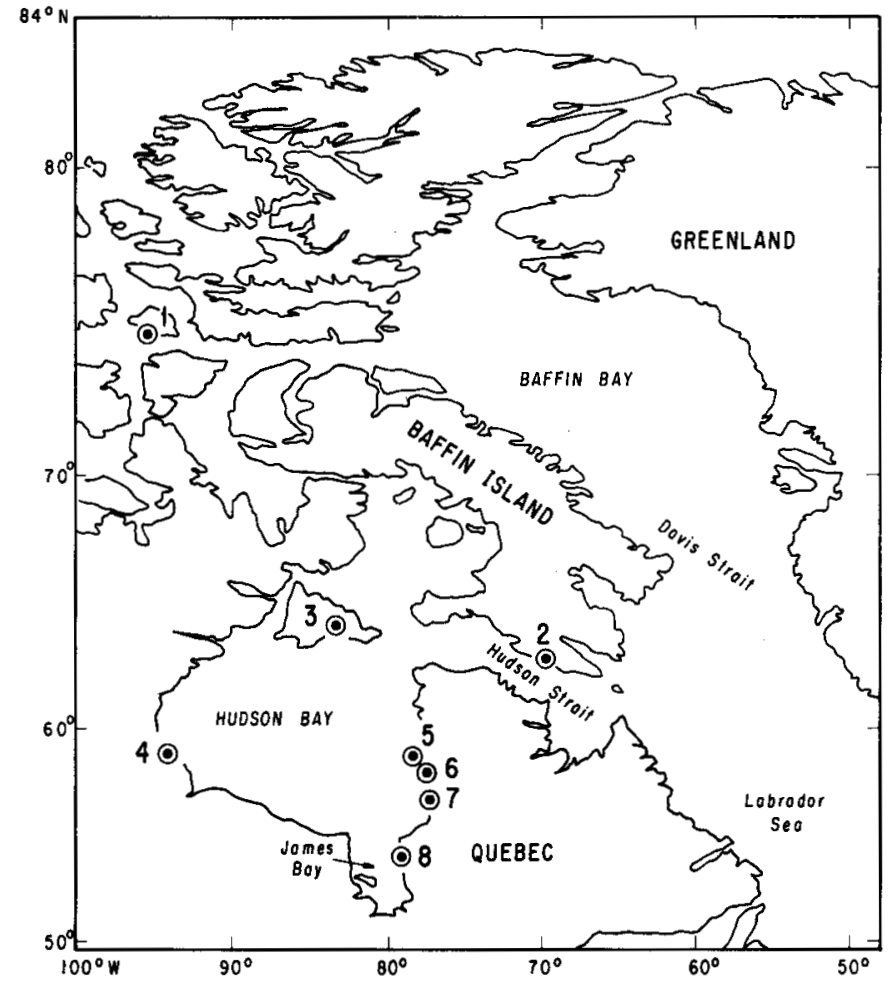

FIG. 1. Map of the eastern Canadian Arctic showing the location of the gauging stations discussed in the text. 1 - Resolute, N.W.T. 2 - Lake Harbour, N.W.T. 3-Coral Harbour, N.W.T. 4-Churchill, Manitoba. 5-Inoucjouac, Quebec. 6- McTavish Island, N.W.T. 7 - Anderson Island, N.W.T. 8 Fort George, Quebec.

$Z(s)=Z_{x y}(s) / X(s)$ : it is determined by the cross spectrum $Z_{x y}$ of the two series and the power spectrum $X$ of the control data. It has an amplitude $|Z(s)|$ and a phase, $\arg Z(\mathrm{~s})$, over a given fre-

\footnotetext{
${ }^{1}$ Visting professor September 1984-May 1985, Centro de Investigaciones Cientificas y de Educacion Superior de Ensenada (CICESE), Ensenada, BC, Mexico. Correspondence address: 2936 Arles Mews, Mississauga, Ontario, Canada L5N 2N2

(CThe Arctic Institute of North America
} 
quency band s. If the components of the series investigated fluctuate, the sample values of the admittance will reflect these fluctuations. In tides, the energy is concentrated in two bands, the diurnal and the semidiurnal. Monthly samples of the admittance are taken in order to follow seasonal changes in the signal, and I calculated the admittance over band widths of 1 cycle $\cdot \mathrm{d}^{-1}$ (coarse resolution). A decrease in the amplitude of the admittance means that the component has decreased for this particular month, and an increase in phase means that its arrival at the station investigated was delayed, using the regular signal at the reference station as a gauge. I experimented with different reference stations to test whether their location affected the results: observed levels and predicted tides at both Vancouver and Halifax were tried. All inputs confirmed the same trends; any of the four inputs could have been used, though the predicted tide at the reference station gave more stable estimates than the observed levels. The results presented here are based on the predicted tide at Halifax serving as a reference signal.

The tide being a deterministic signal, the admittance estimates should be strictly repeatable from sample to sample in an undisturbed tidal record. In fact, this is not quite the case as additional factors affect the observed water level. The only practical way of investigating the range of variation of the admittance is to scrutinize results from long series. Bendat and Piersol (1966) suggest error limits based on the magnitude of the coherence $\left|Z_{x y}\right| \sqrt{X Y} \mid$, where $Y$ is the power spectrum of sequence $y$, assuming that the signal is Gaussian. Empirical evidence indicates that these limits are too broad for tidal records and that the admittance estimates are more stable than the theory implies. In the present investigation, the changes in admittance are usually larger than the limits suggested by Bendat and Piersol, thus confirming their genuine existence.

The stations investigated were (Fig. 1):

1. Resolute, outside the system;

2. Lake Harbour, at the mouth of Hudson Strait;

3. Coral Harbour, at the northern end of Hudson Strait;

4. Churchill;

5. Inoucjouac;

6. a short series at McTavish Island;

7. a short series at Anderson Island; and

8. Fort George, in James Bay.

Most of the data originate from conventional gauges; the records for Inoucjouac, Fort George, and the two islands were obtained from submerged gauges.

Despite the importance of Coral Harbour, it eventually had to be eliminated from the study because of the poor quality of the data.

\section{RESULTS}

The results on the diurnal band for the stations retained are ambiguous because the signal is so small in the area investigated. Its amplitude is $\sim 25 \mathrm{~cm}$ near Resolute and is reduced to a few $\mathrm{cm}$ inside Hudson Bay. The admittance estimates indicate that the diurnal amplitude is virtually constant at the sites where it could be calculated with some confidence. The phase does oscillate with some cyclical regularity; this may be due to the interference of $K_{1}$ and $P_{1}$, two close harmonics that cannot be separated from a month of observations.

The semidiurnal band results are easier to interpret because of the intensity of the signal. The raw product is a sequence of monthly samples of the amplitude and phase of the admittance between the observed water level and the synthesized signal at the reference station. I calculate first the mean annual value of the amplitude samples: this gives the average strength of the local tide. Then I calculate the ratio of the monthly samples to the mean value, obtaining a set of numbers smaller or larger than 1. These ratios are shown in the upper part of Figure 2, each plot

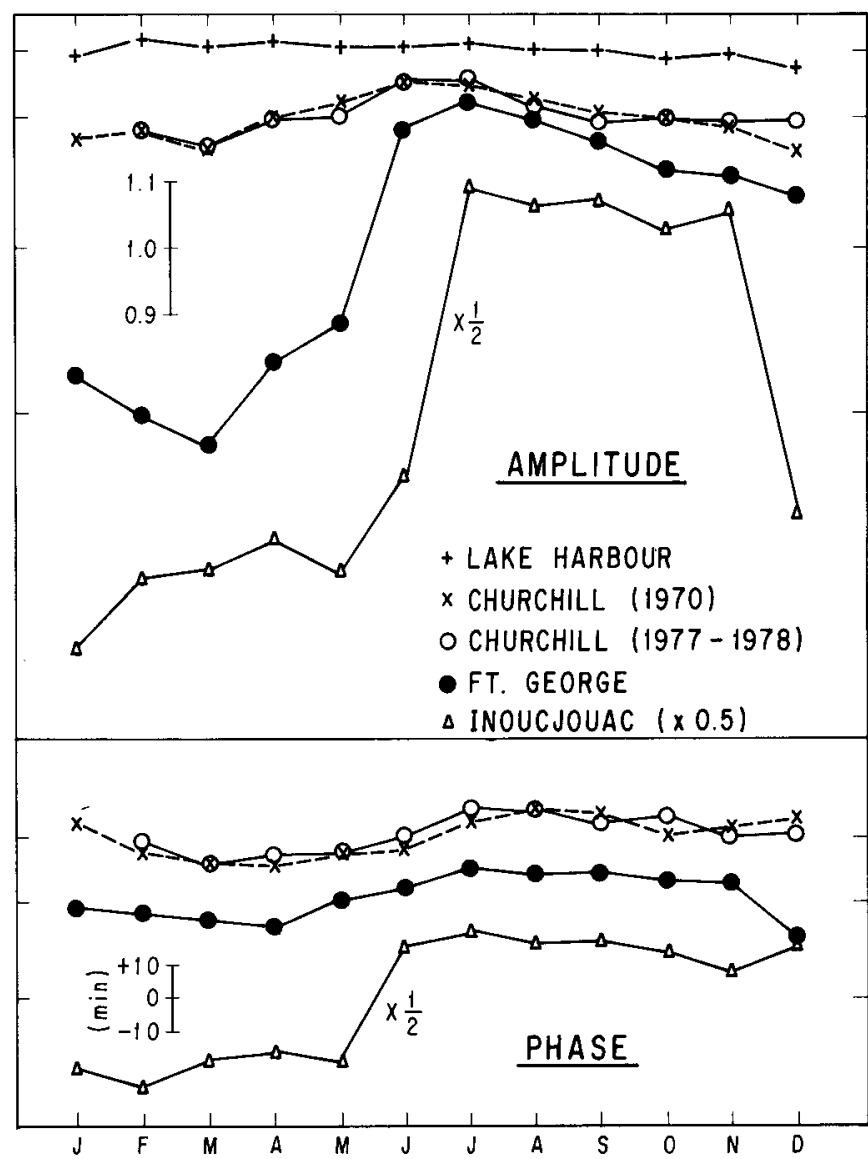

FIG. 2. Ratio of the monthly estimate of the admittance amplitude to its mean annual values (upper diagram), difference between the monthly estimates of the phase and its mean value in minutes (lower diagram). The horizontal mark indicates the position of the mean value. In the upper diagram the graphs, from top to bottom, refer to Lake Harbour (1974), Churchill (1970, dotted line, Sept.-Dec. 1977, Feb.-Aug. 1978), Fort George (submerged gauge, Sept. 1977-Aug. 1978) and Inoucjouac (submerged gauge, same interval). The lower diagram omits Lake Harbour, which exhibits no clear trend. The values for Inoucjouac have been reduced by a factor of .5 .

having its own scale whose origin is indicated by a dash on the frame of the diagram, while inside it the scale of the deviations is shown. I show two sets of samples for Churchill, one for the year 1970, the other covering the interval September 1977-September 1978, the last month being incomplete. This helps check on the repeatability of the changes at a given station. In the case of Inoucjouac, the deviations are so large that their scale has been reduced by .5 . The timing of the semidiurnal tide is determined by the phase of the admittance, which measures the time difference (in angular measure) between the peak values of the signal at the site investigated and at the reference station. The absolute value of this phase differs for each reference station selected and is basically not relevant to the present investigation: we are mainly interested in the fluctuations of this phase, which reflect accelerations or delays in the arrival of the semidiurnal tide at the site. As a consequence I calculate the 
mean annual values of the phase of the admittance, and afterward I calculate the deviation of the monthly samples from this mean value. These are translated into time (minutes) using the equivalence $1^{0}=2 \mathrm{~min}$; they are shown in the lower panel of Figure 2, each station once again having its individual scale, whose origin is marked on the diagram. The inset gives the range of deviation. The deviations of Inoucjouac were reduced by .5 , as in the upper panel. We now review these results, starting with Resolute (not illustrated).

The amplitude at Resolute during 1974 diminished by $2.5 \%$ in June-July and by $3 \%$ in October. The phase shows a slight increase of some $5^{\circ}(10 \mathrm{~min}$ of time) during September-October (i.e., the tide is delayed during the open-water season). In Figure 2 the amplitude at Lake Harbour exhibits slight fluctuations for 1974 , but they show no seasonal cyclicity.

At Lake Harbour $2 \%$ of the amplitude amounts to $7 \mathrm{~cm}$ because the mean semidiurnal amplitude is $350 \mathrm{~cm}$; such fluctuations are barely visible in the diagram because of their small relative magnitude. Clear seasonal periodicities are visible in both amplitude and phase at Churchill; the percentage changes translate to $+10 \mathrm{~cm}$ in amplitude, and the phase indicates a delay of $20 \mathrm{~min}$ during the open-water season. The magnitude of the change differs for the two years and may be linked to the amount of ice. The fluctuations at Inoucjouac are even larger; they amount to $\pm 40 \mathrm{~min}$ in time. The semidiurnal tide at this site is small (mean amplitude $\sim 12 \mathrm{~cm}$ ) because of the presence of a point of amphidromy nearby; the formation of ice must displace this point considerably. The remote station, Fort George, is located at the mouth of La Grande River in James Bay. The amplitude change amounts to $\pm 30 \%$ and implies a change from an amplitude of $40 \mathrm{~cm}$ during the winter to $70 \mathrm{~cm}$ during the open-water season; the tide arrives $\sim 20 \mathrm{~min}$ later in summer. The fragmentary data taken at McTavish and Anderson islands (not shown) during the early months of 1978 give admittance values that decrease in amplitude and phase, reflecting the winter trends of Churchill and Inoucjouac. I have also compared these data with the observed level at Churchill in order to verify if the changes in the tide are uniform throughout Hudson Bay; the comparison suggests that they are not. A similar comparison indicates that the amplitude and phase changes are more rapid at Fort George than at Churchill.

\section{CONCLUSIONS}

Significant changes do occur in the semidiurnal component of the tide at some stations inside Hudson Bay: this component becomes weaker and progresses faster during the ice season. The effect is not noticeable in the mouth of Hudson Strait, whereas it becomes more pronounced on the eastern shore of Hudson Bay and James Bay. It was not possible to detect similar effects in the diurnal component; the amplitude seemed fairly constant but the phase showed some slight cycles. Although these conclusions are based on observations at only a few stations and on data whose reliability could be questioned, the consistency of the results and the magnitude of the changes must reflect an overall modification of the tide inside Hudson Bay by the formation of an ice cover. The range of the tide was always decreased after the formation of ice in all seas where such changes were reported; the data for Coral Harbour as well as theory suggest this should not always be the case. Unfortunately the data for Coral Harbour could not survive elementary tests for quality and reliability. When it comes to changes in the timing of the tide as observed in Hudson Bay, Freeman and Murty (1976) investigated the sensitivity to friction of their model of the tide in this basin; they found that increased friction intensifies the progressive character of the wave. Since the existence of ice alters the overall friction characteristics, it should influence the timing and the strength of the tide. Clearly the time has come to undertake serious theoretical studies on the propagation of the tide in the Canadian Arctic now that we have a rather welldocumented overview of its behaviour throughout the seasons.

\section{ACKNOWLEDGEMENTS}

This paper was written while the author was a visiting professor at the Newfoundland Institute for Cold Ocean Science (NICOS), Department of Physics, Memorial University of Newfoundland, St. John's, Nfld., Canada. Dr. Alex Hay of NICOS steered it through its earlier stages of publication. The original data were processed by the Marine Environmental Data Service, Department of Fisheries and Oceans, Ottawa. The work was completed in Ensenada, B.C., México.

\section{REFERENCES}

BENDAT, J.S., and PIERSOL, A.G. 1966. Measurement and Analysis of Random Data. New York: Wiley. 209-236.

FREEMAN, N.G., and MURTY, T.S. 1976. Numerical modelling of tides in Hudson Bay. Journal of the Fisheries Research Board of Canada 33:2345-2361 .

GODIN, G. 1976. The use of the admittance function for the reduction and interpretation of tidal records. Manuscript Report Series 41. Ottawa: Marine Sciences Directorate, Environment Canada. $46 \mathrm{p}$.

1980. Modification of the tide in the Canadian Arctic by an ice cover. Manuscript Report Series 51. Ottawa: Marine Sciences Directorate, Fisheries and Environment. 29 p.

and BARBER, F.G. 1980. Variability of the tide at some sites in the Canadian Arctic. Arctic 33(1):30-37.

HENRY, R.F., and FOREMAN, M.G.G. 1977. Numerical model studies of semidiumal tides in the southern Beaufort Sea. Pacific Marine Science Report 77-11. Ottawa: Fisheries and Environment. 91 p.

KOWALIK, Z. 1981. A study of the $\mathbf{M}_{2}$ tide in the Arctic Ocean. Modeling, Identification and Control 2:201-223.

ZUBOV, N.N. 1945. The Icing of the Arctic. Moscow: Izdatel'stvo Glavsermorputi. (In Russian.) (Translation \#641, U.S. Navy Electronic Laboratory 328-329.) 